\title{
The hypothesis about the influence of electrical phenomena on geological processes and global disasters
}

\author{
Arkadiy Plugin, Andrii Plugin, Oleksii Pluhin, Dmytro Plugin, and Olga Borziak* \\ Ukrainian State University of Railway Transport, 7 Feuerbach Sq., Kharkiv, 61050, Ukraine
}

\begin{abstract}
Global Warming is officially recognized as one of the aspects to the Earth's climate change; and its major factor is a sharp anthropogenic increase in concentration of greenhouse gases, especially carbon dioxide $\left(\mathrm{CO}_{2}\right)$. However many scientists do not agree with this view and do not consider the anthropogenic factor as its basic reason, thus regarding measures for limiting greenhouse gas emissions as useless. The authors believe that a real reason is lack of unequivocal ideas in the framework of the Earth Science. The objective of the research presented in the article is to establish true reasons for global catastrophes, global warming, their rapid increase of recent decades, and their hazard level, as well as to reveal their nature and actual mechanisms. The authors critically analyzed and compared the existing data on global processes and catastrophes on Earth from ancient times to nowadays, revealed their actual mechanisms on the basis of Submicro- and Macrocolloid Chemistry and Physical-Chemical Mechanics of Earth, a new science on Earth set up by the authors. The authors demonstrated that the motive power of all global phenomena and processes on Earth is the electric force, conditioned by the surplus negative electric charge of Earth, and the reason of the approaching global catastrophe is an abnormal increase of the charge in recent decades. The article deals with critical analysis of experimental data on dynamics of global catastrophes, among them the change in Earth's temperature and level of ocean, a greater amount of carbon gas and atmosphere dust.
\end{abstract}

\section{Introduction}

Global Warming is officially recognized as one of the aspects to the Earth's climate change; and its major factor is a sharp anthropogenic increase in concentration of greenhouse gases, especially carbon dioxide $\left(\mathrm{CO}_{2}\right)$. Global warming mainly manifests itself as a rapid increase in Earth's temperature, a change in the warm Gulf Stream current, etc. of last decades. International treaties recognize that the key measure to prevent the warming is compulsory reduction of greenhouse gas emissions, which consumes huge funds and physical recourses. However, many scientists do not agree with this view and do not consider the anthropogenic factor as its basic reason, thus regarding measures for limiting greenhouse gas emissions as useless. Many people can realize the approaching catastrophe but they do not know how to resist and what they should do. According to some researchers the reason of global warming is lack of veritable knowledge about the world and man. We believe that a real reason is also lack of unequivocal ideas in the framework of the Earth Science.

Unlike the existing science and "alternative" sciences, the authors established an actual reason and revealed the mechanism of these global cataclysms and natural disasters, revealed mechanisms of the Earth development and imminent global catastrophes, and, furthermore, critically analyzed existing experimental data on the global catastrophes' dynamics.
In recent decades the number of natural disasters in the world has rapidly increased.

It is considered that the reason is in the Earth's global climate change, in particular, a higher temperature and the anthropogenic increase in the greenhouse gas concentration since 1960 , especially $\mathrm{CO}_{2}$ and methane $\left(\mathrm{CH}_{4}\right)$, (it is shown in Fig. 1 as the first maximum), a change in the warm Gulf Stream current, etc. As it was mentioned above, international treaties (the Kyoto Protocol of 1999, the Paris Agreement of 2015) consider a compulsive reduction of greenhouse gas emissions as the key measure to prevent these catastrophes; therefore, this requires great funds and physical recourses.

However, there are some other views on the problem. As many scientists think, particularly in [1-3], Earth's global warming has not been caused by the $\mathrm{CO}_{2}$ emissions to the atmosphere, but, on the contrary, by a higher temperature of Earth; as there is no record about anthropogenic contribution into an average annual temperature rise on Earth, we can suppose that the international treaties are not practical and rather useless. We believe that the reason is lack of the genuine knowledge about the world and man, and, actually, the erroneous nature of the Earth Science.

\section{Research methodology}

The methodology of the research is based on Submicro-

\footnotetext{
* Corresponding author: borziak.olga@gmail.com
} 
and Macrocolloid Chemistry and Physical-Chemical Mechanics of Earth, a new science established by the authors that was published in book "Submicro- and Macrocolloid Chemistry and Physical-Chemical Mechanics of the Earth" in 2016. The science is based on laws and regularities of Colloid Chemistry and PhysicalChemical Mechanics of Dispersed Systems and applied to subjects of inquiry of the submicro- and macrocosms. Their applicability is conditioned by the fact that Colloid Chemistry and Physical-Chemical Mechanics [4, 5] considers the surface phenomena, in particular, electrosurface characteristics of disperse systems. Earth is also considered a disperse system, with a scale of $<10 \AA$ and $>>1 \mu \mathrm{m}$, going far beyond the colloid sizes $(10 \AA \div$ $1 \mu \mathrm{m})$, where electrical surface phenomena, processes and regularities are also prevalent.

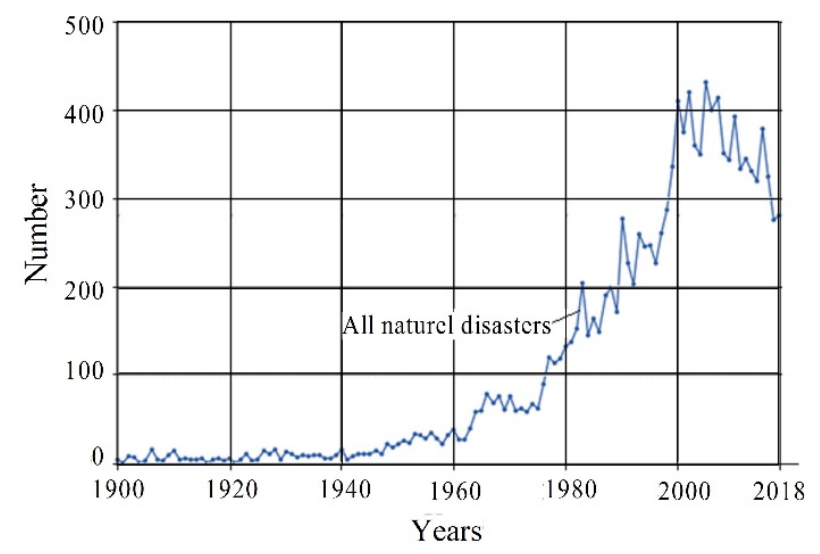

Fig. 1. Number of reported disaster events: drought, floods, extreme temperature, landslides, wildfires, volcanic eruptions, earthquakes and other. Source: EM-DAT (2019):

OFDA/CRED International Disaster, Universite catholique de Louvain- Brussels-Belgium.

The used methods are theoretical and analytical and based on generalization and critical analysis of existing literature data in the field of global phenomena and processes on Earth. Regularities that are used for analysis: Coulomb electrostatic forces, polarization, diffusion, osmosis, capillary rise, etc.

\section{Analytical review}

Previously, the authors on the basis of the provisions of colloid chemistry and physico-chemical mechanics have studied the electrical effects on building structures and materials. For example, the construction of electrified railways, which are operated under the conditions of electrical influences from sources of direct [6] and alternating current [7]. It was shown and experimentally proved in [6] that under the influence of a pulsating unidirectional electric potential and the corresponding current flowing during the passage of trains, concrete and masonry mortar also undergo electrocorrosion. Electrocorrosion consists in electromigration leaching of $\mathrm{Ca}(\mathrm{OH})_{2}$ [6] and the formation of cracks [8-10], the intensity of which depends on the current strength [6]. It was shown in $[6,10,11]$ that the electrical effects on concrete and structures made of it are not only electric potentials and leakage currents, but also excess electric charges. Excessive charges are formed during the macropolarization of objects, both artificial and natural, from the unevenness of the Earth's electric field on the ground, from the transfer of cations of soils, rocks and concrete by ground and underground waters, temporary and permanent streams. Based on electrical measurements, schemes have been developed for the flow of leakage currents from rails of an electrified direct current railway track through structures that are in good agreement with the nature of corrosion damage. The effect of excess electric charges on the decrease in tensile strength of concrete [10], the deterioration of the physical and mechanical properties of soils as a result of their liquefaction [11] was experimentally confirmed.

Based on the understanding of these phenomena and processes, means have been developed to protect structures from electrical influences in the form of anodic or cathodic electrochemical protection, electro-drainage [12], grounded electrically conductive screens [6] or screens made of electrically conductive compositions based on mineral binders $[6,13]$ with simple or diode grounding, which drains leakage currents and stray currents. To protect structures from such currents it was proposed in $[14,15]$, to use screens-coatings with a polymer-cement mortar with increased electrical resistance, which will impede the flow of currents through the structure or reduce their strength.

By analogy with the proven regularities of electrical effects on building materials and structures, as well as the soil of the foundations, a hypothesis is put forward on the effect of electrical phenomena on geological processes and global disasters.

\section{Results of research}

On the basis of Submicro- and Macrocolloid Chemistry and Physical-Chemical Mechanics of Earth the authors revealed mechanisms of global phenomena and processes on Earth, such as a rapid growth in the number of natural disasters and catastrophes of recent decades, a higher temperature and greenhouse gasses (global warming), change of the warm Gulf Stream current, etc. In order to reveal these phenomena and processes and estimate their hazardous degree for the present civilization, the authors generalized and critically analyzed the global cataclysms and processes of ancient times, namely, the change in global temperature, the Sun's activity, greenhouse gasses, atmosphere dust, ocean level, extinction (or rather, disappearance) of organisms and humans, formation of supercontinents and their disintegration into continents, etc.

The moving force of the mechanisms and other phenomena and processes on Earth and beyond is the electric force induced by the surplus negative electric charge of Earth, and the reason of the approaching global catastrophe is an abnormal rise of this charge in recent decades.

The basic source of the charge is the thermal diffusion of electrons from the molten Earth's core as a result of a very big difference of temperatures in Earth's core (about 
$\left.6000{ }^{\circ} \mathrm{C}\right)$ and on Earth's surface $\left(14^{\circ} \mathrm{C}\right.$ on the average), Fig. 2.

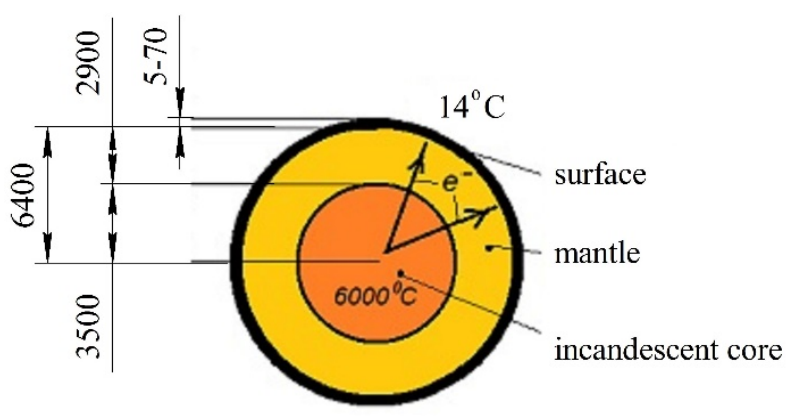

Fig. 2. Diagram of the excess negative charge of the Earth due to thermal diffusion of electrons from its red-hot nucleus to the surface

Such a notion of the surplus negative charge of Earth correlates with a diagram of Earth's spherical capacitor reproducing the hypothesis on ionosphere put forward by Nikola Tesla. It creates in the upper layers of Earth and its atmosphere the electric field, with the experimentally found average potential $E=-130 \mathrm{~V} / \mathrm{m}$ (corresponds to the equilibrium surplus negative charge), and near Earth's surface it changes from -1000 to $+200 \mathrm{~V} / \mathrm{m}$.

Very intensive sources of Earth's surplus negative charge are also the Secular Sun's Activity and the periodic 11-year Sun's activity, Fig. 3, a.

In recent decades the most intensive source of the surplus negative charge has become space launchings (since 1957), from Cape Canaveral Air Force Station, the John F. Kennedy Space Center and the Wallops Flight Facility, mass launches of the super heavy Space Shuttle systems, and also Chinese rockets (Fig. 3, b, c and d, respectively). During the launch of a rocket, especially a heavy one, and the combustion of rocket fuel, a significant separation of electric charges occurs between the earth and the upper atmosphere.

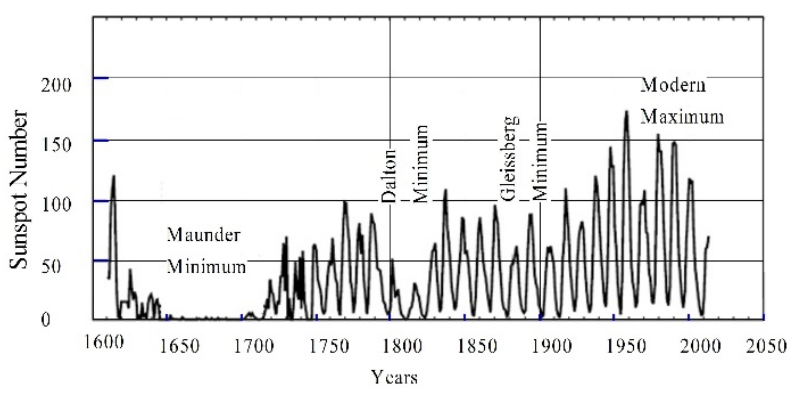

$a$

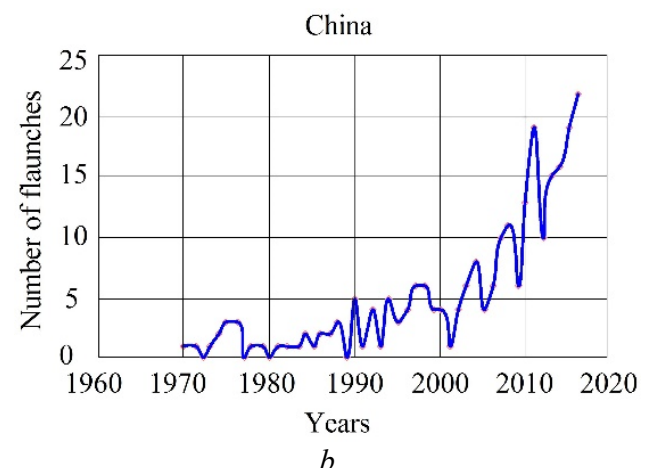

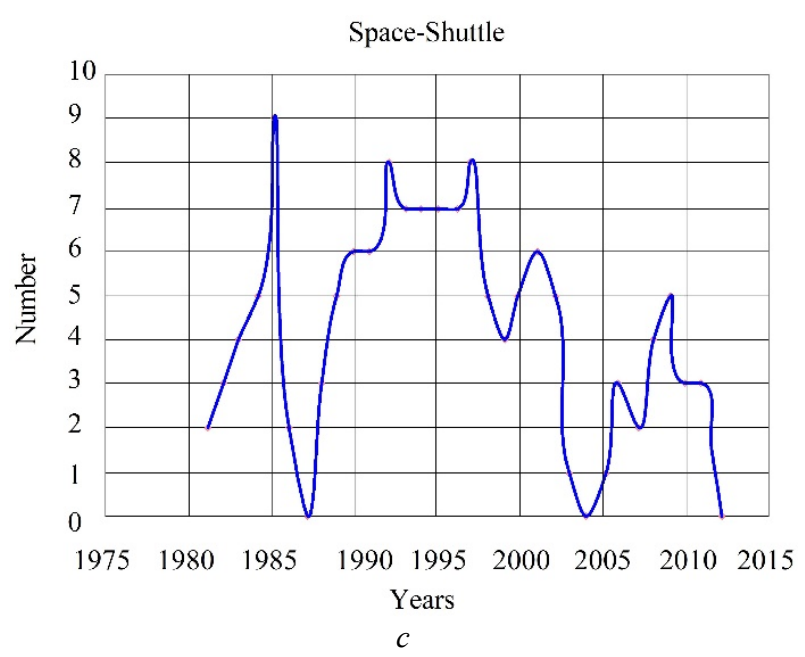

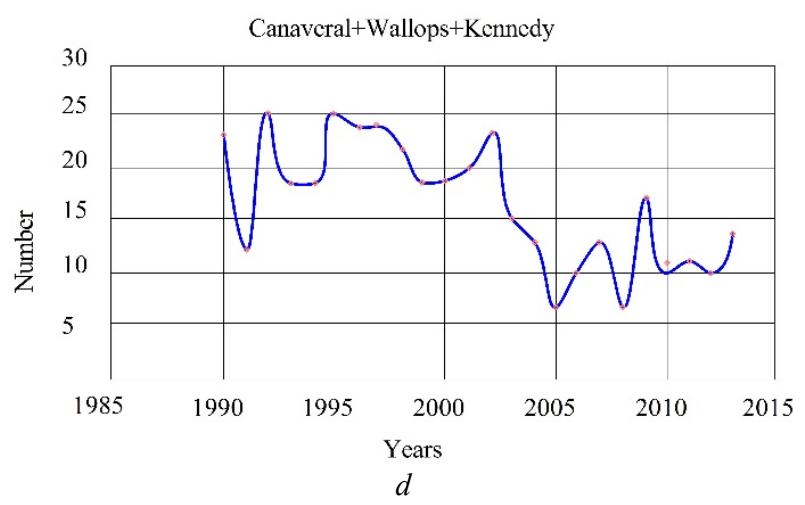

Fig. 3. Space rocket launches: a - the Secular Sun's Activity and cycles of the 11-year Sun's activity. Compiled by [1]; b rocket launches of 1970-2017 by China; c - rocket launches the Space Shuttle systems in 1981-2012; d - rocket launches from Cape Canaveral Air Force Station, the John F. Kennedy Space Center and the Wallops Flight Facility.

\section{Mechanisms of the earth development and increasing global catastrophes}

Let us consider mechanisms of basic processes and phenomena of the Earth development and imminent global catastrophes. The Earth's evolution has been accompanied by catastrophic processes for all living beings.

The surplus negative charge as the motive force for absolutely all global processes became apparent from the formation of Earth at least 5.5 billion years ago. Earth was formed when part of the accumulated surplus charge of the Sun as a molten mass corresponding to Earth's mass emitted to the Earth's orbit; it was provoked by thermal diffusion of electrons of the Sun (in the core the temperature is about $10,000,000,000{ }^{\circ} \mathrm{C}$ and outside $\left.6,000{ }^{\circ} \mathrm{C}\right)$.

About 1.4 billion years later in the cosmic vacuum with a temperature of $2,725 \mathrm{~K}$ (about $-270{ }^{\circ} \mathrm{C}$ ) the Earth surface with the world ocean became cool to the normal temperature and the first supercontinent Vaalbare appeared, Table 1.

Then, due to the constantly running thermal diffusion of electrons, a huge surplus negative charge accumulated under Earth's crust, the crust of the supercontinent 
softened and fractures developed in it. These fractures accumulated the surplus negative charge of a very high concentration thus separating formed parts of the supercontinents great distances apart. And the supercontinent split into continents. It took about 100 million years.

Table 1. Formation of Supercontinents of Earth.

\begin{tabular}{|c|c|c|}
\hline No & $\begin{array}{c}\text { Supercontinents and Continents, } \\
\text { years (billion/million years ago) }\end{array}$ & $\begin{array}{c}\text { Beginning of existen- } \\
\text { ce (disintegration } \\
\text { duration) }\end{array}$ \\
\hline 0 & Earth, 4-5 & 1.4 \\
\hline 1 & Vaalbara, 3.1-2.8 & $0.4(0.1)$ \\
\hline 2 & $\begin{array}{c}\text { Kenorland, 2.7-2.5 } \\
\text { (disintegration) }\end{array}$ & $0.9(0.7)$ \\
\hline 3 & Nuna (Columbia), 1.8--1.5 & $0.7(0.4)$ \\
\hline 4 & $\begin{array}{c}\text { Rodinia, 1.1 - 750 (disintegration } \\
\text { of the previous one) }\end{array}$ & $0.5(0.15)$ \\
\hline 5 & $\begin{array}{c}\text { Pannotia, 600-540 } \\
\text { (disintegration) }\end{array}$ & $0.3(0.24)$ \\
\hline 6 & Pangaea, 300-180 & $0.235(0.115)$ \\
\hline 7 & Present Earth, 65 \\
\hline
\end{tabular}

All these transformations of supercontinents and continents went along with influences of gigantic forces and cataclysms, when life could not exist yet. For the first time, as known, about 525 million years ago living beings appeared, and animals, such as amphibian and reptiles, about 300 million years ago, Fig. 4 .

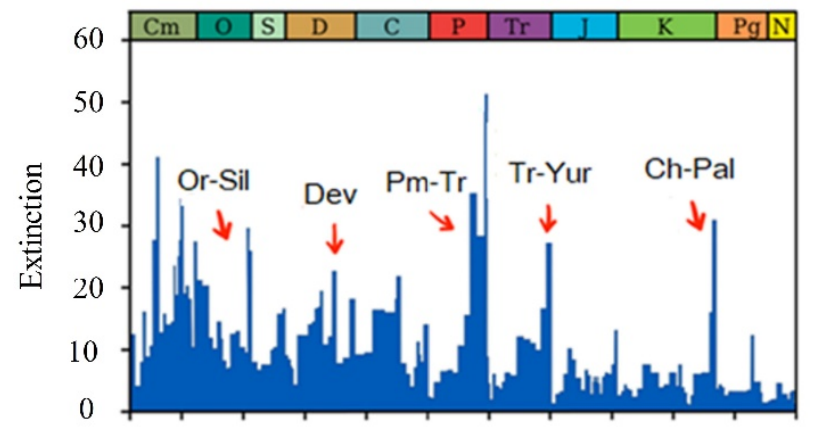

$\begin{array}{lllllllllllll}542 & 500 & 450 & 400 & 350 & 300 & 250 & 200 & 150 & 100 & 50 & 0\end{array}$

Mln Years Ago

Fig. 4. The great extinctions of organisms on Earth during the period from 542 million years $\mathrm{BC}$ to present [16].

During their life the organisms regularly died out and disappeared, it might happen even on a massive scale: 1. The Ordovician-Silurian extinction events, 440 billion years ago (got extinct more than $60 \%$ of sea invertebrates).

2. The Late Devonian extinction, 380 million years ago (the number of marine communities reduced by $50 \%$ ).

3. The Great Permian Extinction, 265 million years ago (got extinct more than $95 \%$ of all living organisms).

4. The Triassic-Jurassic extinction event, 210 million years ago (died out more than $50 \%$ of all types of living organisms known at present).

5. The Cretaceous-Paleogene, 65 million years ago (died out dinosaurs and $70 \%$ of all types of living organisms).

Life on land and relatively big animals appeared in the Carboniferous period. It is believed that the man appeared
2 million years ago.

Virtually all ancient developed civilizations, and there were several of them, disappeared. Nevertheless, they left for us megalithic structures build in recent ten-twenty millenniums, whose construction technologies cannot be applied at present.

One of the reasons why animals and people died out is also considered the constantly recurring Ice Ages or Glacial Periods (millions of years in duration).

Thus, the analytical research, presented in this section, confirmed that Earth's global processes (extinction of living organisms and people, and, consequently, vegetation, formation of continents and glaciers, orogenic processes, etc.) were chiefly caused and regulated by the periodically accumulated and dropped a huge surplus negative charge in the Earth's surface layers.

The fact, that most types of people ever lived on Earth became extinct, affords ground for a number of researchers to assume that all types of life have a limited period, and human extinction is inevitable (i.e. mankind always runs risk to die out) [17].

The significant factors of the global climate change on Earth are considered a rapid increase in temperature and greenhouse gasses, first of all, $\mathrm{CO}_{2}$, and a change in the Sun's activity, Fig. 5.

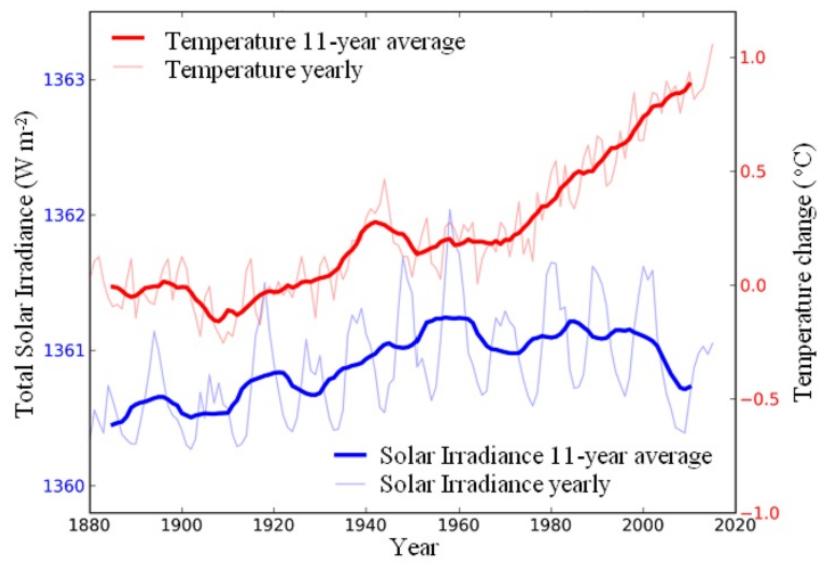

$a$

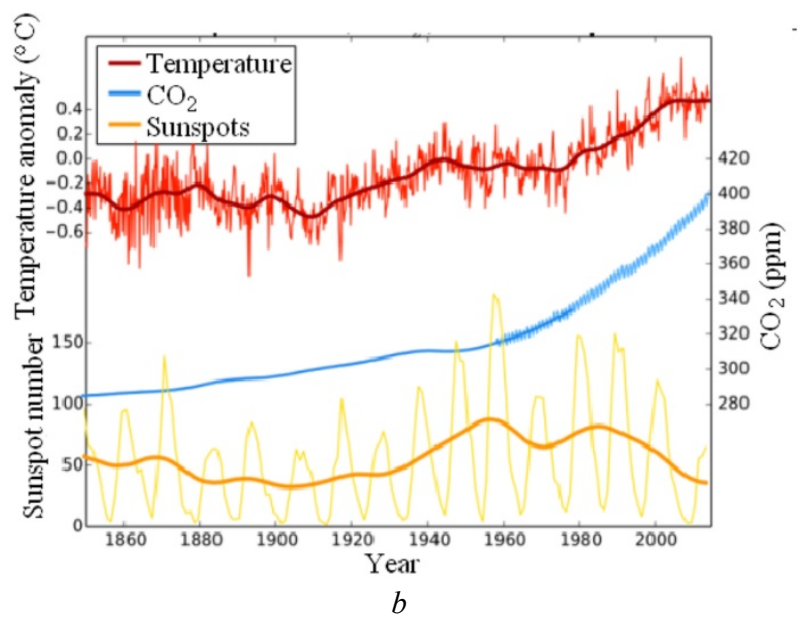

Fig. 5. Annual global temperature, Solar Irradiance and $\mathrm{CO}_{2}$ change: a - compiled by Solar vs TemperatureSkeptical Science; $b$ - schedule from Global Warming - Research IssuesStanford Solar Center. 
Furthermore, “... last several hundred years the number of sunspots has constantly grown, and Earth has become warmer...", however since 1980 such a pattern has broken. Consequently, the Sun cannot be the main temperature regulator.

The relation between the Earth temperature, $\mathrm{CO}_{2}$ concentration, and the number of sunspots testifies to their increase in concord and in cycles (Fig. 5). And diagrams in Fig. 6 presenting the last 400 and 800 thousands of years, based on diagrams from ice cores from Antarctica confirm it.

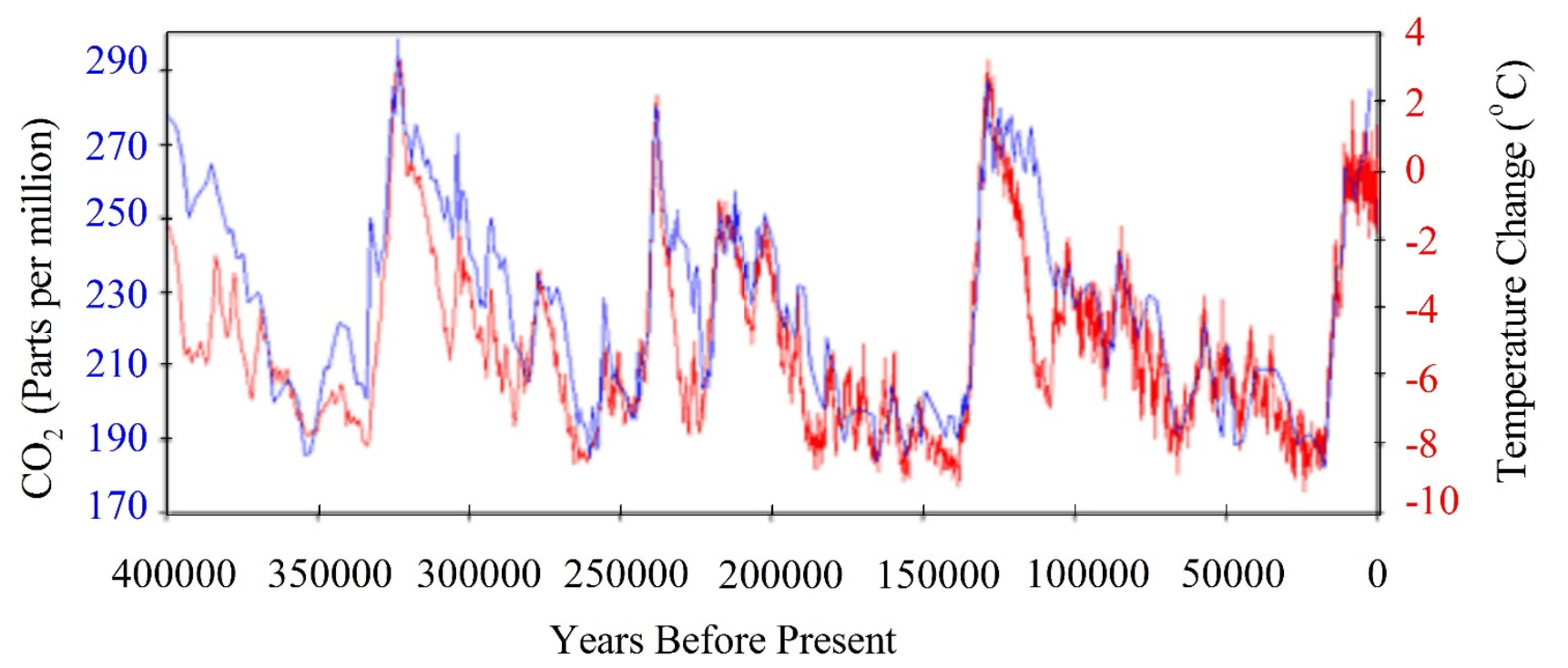

Fig. 6. Vostok ice core records for carbon dioxide concentration and temperature change $\left(\mathrm{CO}_{2}\right.$ lags temperature - what does it mean? Skeptical Science).

However, the concentrations have never reached such high values as we can witness today; this fact gives rise to serious concern of many researchers, Fig. 7.

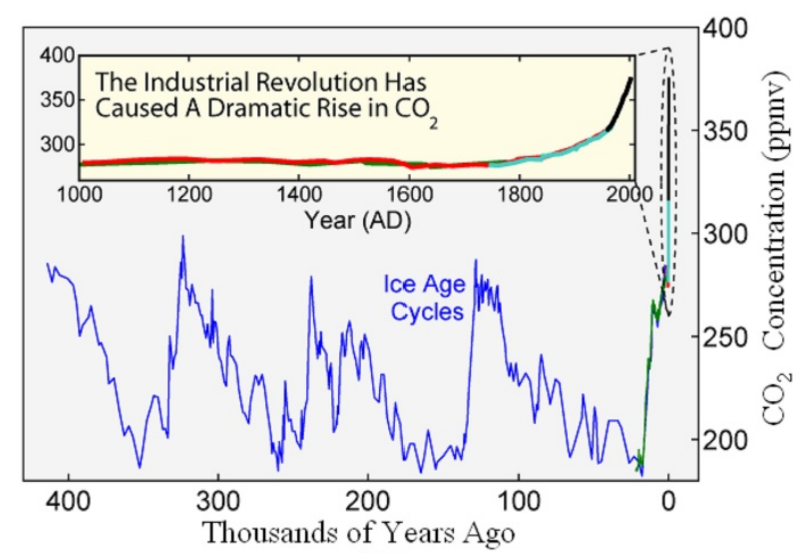

Fig. 7. The change in the content of carbon dioxide $\left(\mathrm{CO}_{2}\right)$ during the last 400 thousand years and to present.

According to [18] "... the shape of a temperature curve advances the curve presenting the $\mathrm{CO}_{2}$ changes by approximately 5-8 thousand years at the time when waters of the world ocean, the main reservoir of free $\mathrm{CO} 2$ on Earth, completely got mixed (now the world ocean has approximately 60 times more of $\mathrm{CO}_{2}$ dissolved than that in the atmosphere)".

According to diagrams presented, the concentrations of carbon dioxide (as methane) fluctuated in right cycles with a period of about 100,000 years. However, a more attentive study reveals that the $\mathrm{CO}_{2}$ change actually follows the temperature change, with a delay close to one indicated.
The global temperature growth was also followed by an ocean level fall to approximately $100 \mathrm{~m}$, Fig. 8 .

The indicated periodic change in carbon dioxide $\left(\mathrm{CO}_{2}\right)$ due to its greater content in the ocean is conditioned by an increase in the surplus negative charge in the surface layer of the ocean water. It results in better solubility and increased concentration of $\mathrm{CO}_{2}$ (mostly hydro carbonates and bicarbonates) in the ocean waters when $\mathrm{CO}_{2}$ transfers to the atmosphere). A decrease in the surplus negative charge leads to crystallization of solution products. Accordingly, an increase or a decrease in the surplus negative charge during a long period (100 thousand years in average) leads to a cyclic long-term change in the temperature.

Accumulation of the surplus negative charge in Earth in recent decades, and thus, Earth's warming is the result of excessive rocket launches; and this leads to another Global catastrophe on Earth. Here, we can conclude that the $\mathrm{CO}_{2}$ input into the atmosphere is not anthropogenic by nature, but the cause of Earth's warming is a huge increase in the surplus negative charge.

By the way, with an increase in the surplus negative charge in the ocean waters, not only $\mathrm{CO}_{2}$ transfers to the atmosphere, but also the water itself; it happens due to its much more intensive evaporation, therefore water vapor is the most powerful greenhouse gas.

The data on long cyclic changes in both the amount of dust in the atmosphere and temperature cycles in ancient times and now obtained from ice cores of Antarctica are of considerable importance for studying Earth's global cataclysms, Fig. 8, Fig 9.

Such a substantial fall of the ocean level was conditioned by the previous rapid increase in the surplus 
negative charge of Earth, which raised the ocean and sea waters along the soil capillaries by the macro electroosmosis mechanism, thus lowering the ocean water level.

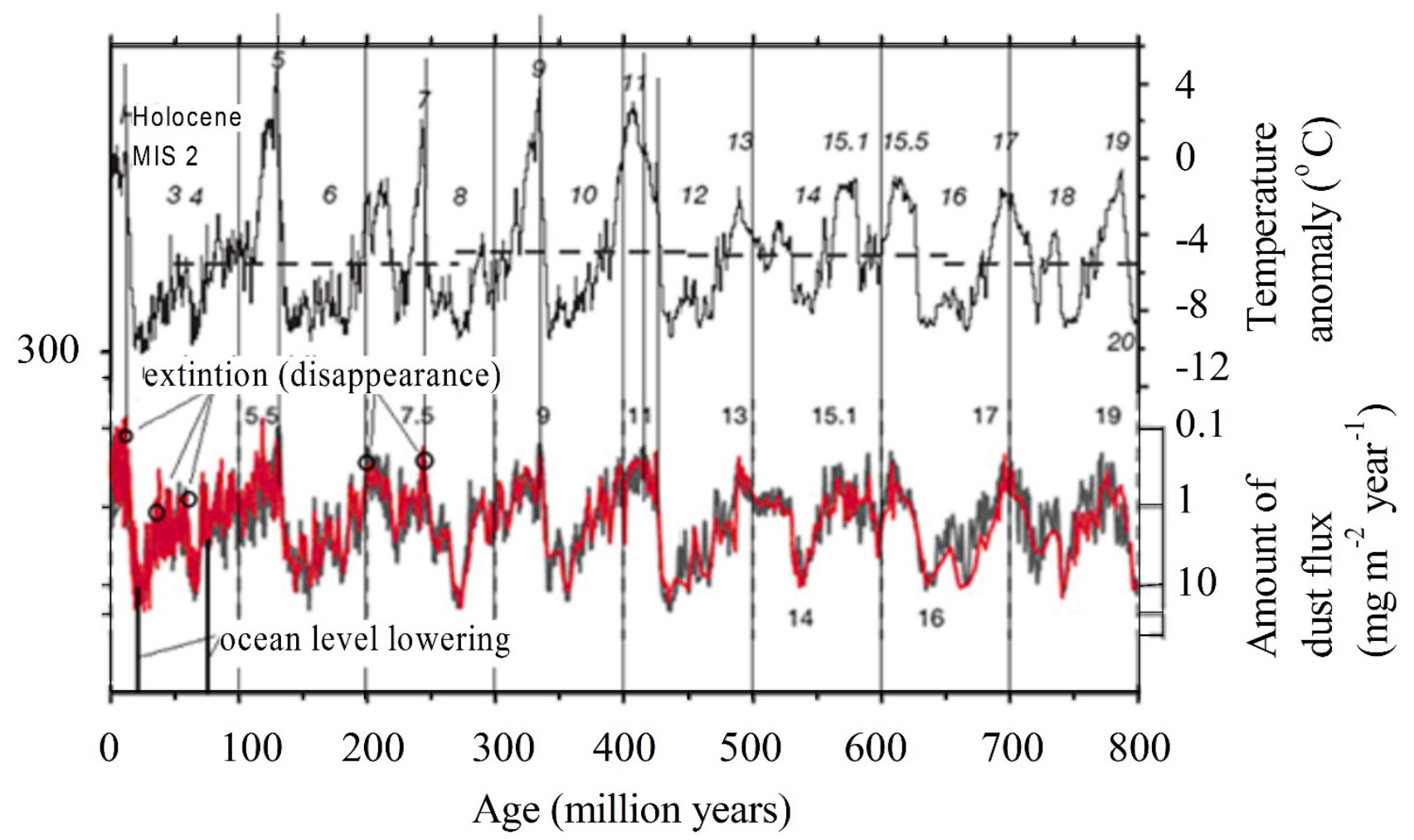

Fig. 8. The long cyclic changes in temperature and amount of dust in ice cores (atmosphere) during 800 million years (based on diagrams of [19] and [20]).

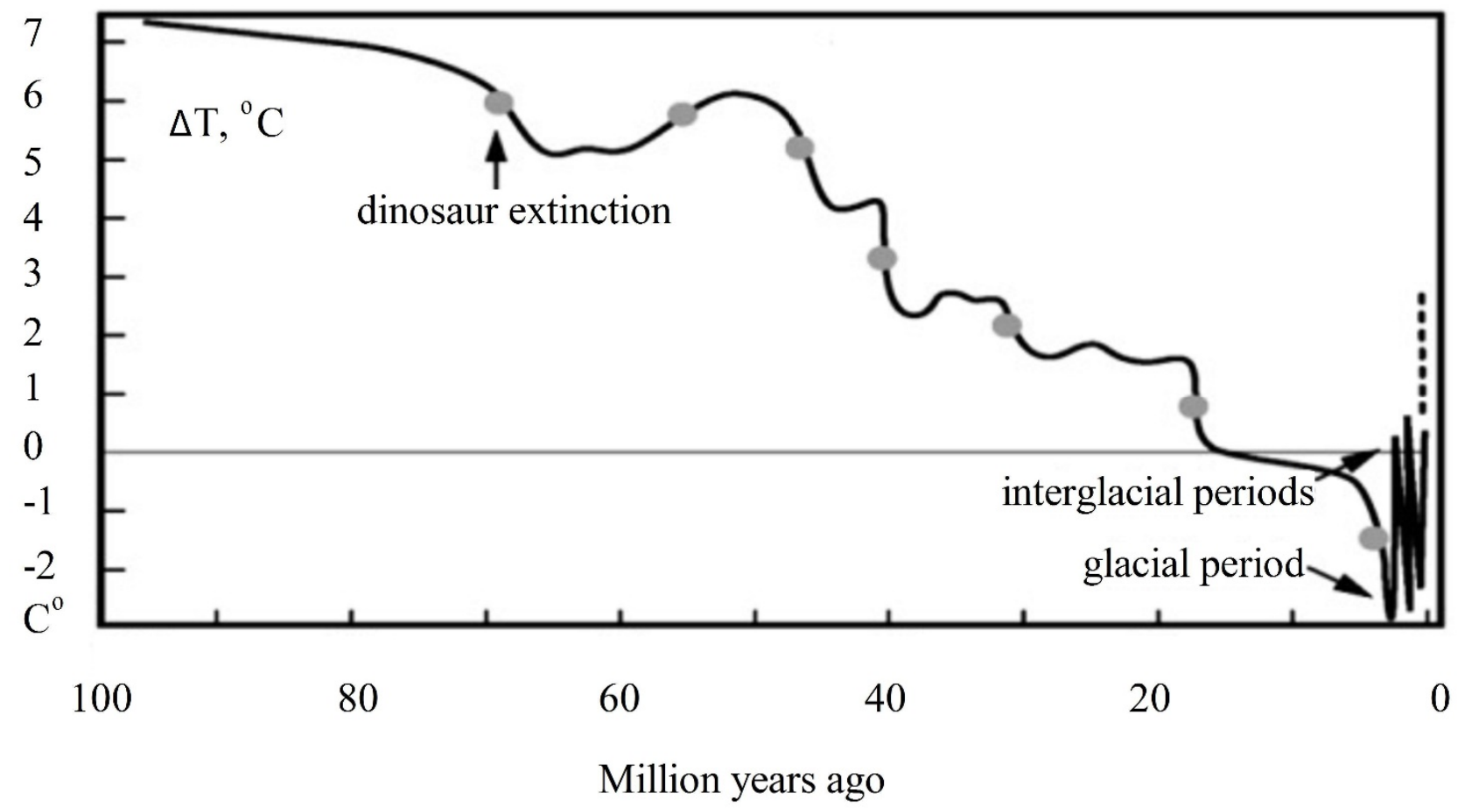

Fig. 9. The change in Earth's temperature from 100 million years ago to 0.5-3.5 billion years ago (the diagram is corrected by the period of dinosaur extinction -65 million years ago) [16].

The surplus negative charge accumulated on soil and soil particles repulsed, the soil became loosened and atomized, and lost its cohesion. Their large surplus negative charge led also to emergence of repulsive forces to the large negative charge in the Earth's surface layer. This force exceeded the gravitational force, and then the soil particles and the surface layer tore off and carried along virtually everything off the surface. 
At earlier stages of its existence (0.5-2.25 billion years ago) the Earth temperature was about $25-47{ }^{\circ} \mathrm{C}$ with the maximum 1.75 billion years ago [21], which was quite acceptable for the beginning of life, especially in ocean. And in the earliest years of its existence, 2.25-3.5 billion years, the temperature was considerably higher, up to 70 ${ }^{\circ} \mathrm{C}$, which was incompatible with life of most living organisms. The minimal temperature of $5{ }^{\circ} \mathrm{C}$ (about 65 million years ago) in the diagram (Fig. 9) when dinosaurs disappeared, coincides with the minimal ocean level (Fig. 8). Apparently, the second maximum ocean level (450 million years ago), Fig. 10, also coincided with the maximum temperature, this tendency manifested itself as the beginning of a temperature rise 500 million years ago.

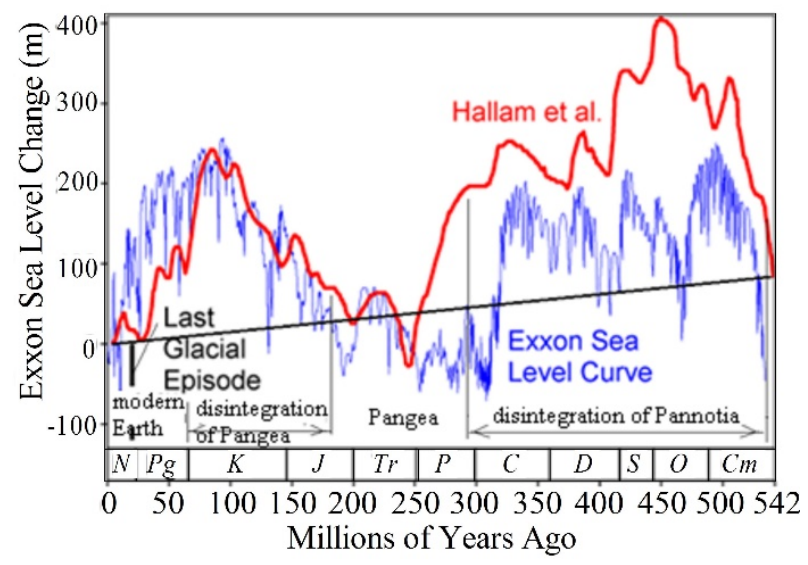

Fig. 10. The change in the ocean level during the period from 540 million years ago (based on the diagram of [20]).

Such a change pattern in Earth's temperature and ocean level confirms that originally the surface temperature was very high, i.e. incompatible with any life on Earth. Approximately by a period of 1.5 billion years ago, the surplus charge of Earth reduced and reached the equilibrium state. Then it began to change in cycles relative to this equilibrium. The maximum negative charge resulted in global catastrophes, and then the surplus negative charge fell and began to rise again due to thermal diffusion of electrons from the Earth's core.

As we can see, the greatest changes in the ocean level coincide with periods of existence of the supercontinents (here, Pannotia and Pangaea, Table, the minimal level) and their disintegration (the maximum level). The mechanism of their disintegration and formation is based on this dependency.

The main role of the surplus negative charge in all the global catastrophes is also confirmed by formation and disintegration of the supercontinents. During all its life the supercontinent accumulated a huge surplus negative charge underneath, and gigantic stretching forces grew in it. Moreover, the soil of the continent became softer, and the surface layers became loosened, crumbled up and dusted. When the stretching forces reached the limiting values, thus exceeding the supercontinent strength, cracks and splits developed inside, they accumulated a huge surplus negative charge from Earth's core; then the split parts went apart and formed continents.
Enormous amount of dust elevated off the Earth surface that was incomparable with the dust from eruption of the greatest volcanoes, the sunlight could not reach Earth for many million years, and the Earth temperature gradually fell. The cyclic changes in temperature and dust in ice cores of Antarctica convincingly demonstrate it (Fig. 8).

With the lapse of time the enormous surplus negative charge began to accumulate under and inside the formed continents owing to thermal diffusion of electrons from Earth's core. The charges and continents were polarizing acquiring the sequential unidirectional gigantic macro dipole moments towards the equator (due to a lag between the space vacuum and ocean water, and the Earth rotation (and the land on)), as well as in Earth's electric field between the poles. The attraction forces between these dipole moments redistributed the continents; the supercontinents joined and formed the supercontinent Pangaea (Fig. 11).

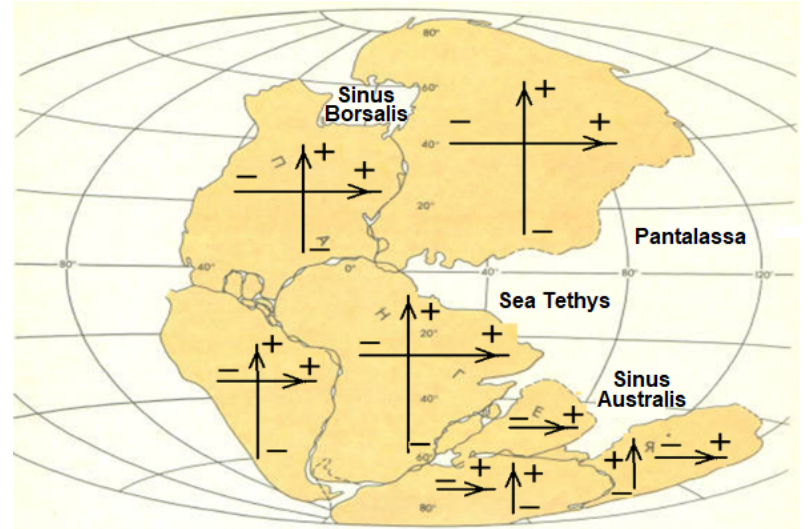

Fig. 11. The continent polarization and huge dipole moments of the continents the attractive forces between which resulted in the formation of the supercontinent Pangaea.

A huge growth in the number of global catastrophes in recent decades, as it was mentioned above, has been conditioned by space rockets launches. The enormous number of these launches and launches of super heavy rockets to the Moon and Mars planned threaten to ruin the civilization in the short run.

\section{Conclusions}

1. Based on the provisions of colloid chemistry and physico-chemical mechanics of disperse systems and materials, a hypothesis has been put forward about the influence of electrical phenomena on geological processes and global catastrophes.

2. It is assumed that one of the moving forces of geological processes and global catastrophes is the excess negative electric charge of the Earth cyclically accumulated as a result of macropolarization phenomena.

3 . The increase in the number of global disasters in recent decades has been influenced by space rocket launches. This effect is due to the fact that as a result of the combustion of rocket fuel, rocket take-off, a significant amount of electric charge is transferred, and it is divided between the earth and the upper atmosphere. A further 
increase in the number of launches and mass of rockets may lead to an increase in the number of catastrophic events.

4. The prevention of catastrophic events is possible based on an analysis of the causes of the accumulation of excess charges, the development and implementation of ways to prevent such accumulation.

This research did not receive any specific grant from funding agencies in public, commercial, or not-for-profit sectors.

\section{References}

1. D.H. Hathaway, Living Rev. Sol. Phys. 12, 4 (2015). doi:10.1007/lrsp-2015-4

2. W.-H. Soon Willie, Variable solar irradiance as a plausible agent for multidecadal variations in the Arctic-wide surface air temperature record of the past 130 years. Geophys. Res. Lett. 32, L16712 (2005). doi:10.1029/2005GL023429

3. S-I. Akasofu, Is the Earth still recovering from the Little Ice Age? A possible cause of global warming. (2008), http://www.wright.edu/ guy.vandegrift/climateblog/ s06/akasofu.LIAge.pdf. Accessed 27 Dec 2019

4. A. Plugin, L. Trykoz et al, Osnovy teorii tverdenija, prochnosti, razrushenija $i$ dolgovechnosti portlandcementa, betona i konstrukcij iz nih. Tom 1. Kolloidnaja himija i fiziko-himicheskaja mehanika dlja cementnyh betonov (Naukova Dumka, Kyiv, 2011)

5. D.A. Friedrichsberg, Kurs kolloidnoj himii. (Khimiya, Leningrad, 1984)

6. O.A. Plugin, O.S. Borzyak, V.B. Martinova, O.A. Halyushev, Elektrichni vplivi na beton (Fort, Harkiv, 2013)

7. O.A. Dudin, Dissertation, Ukrainian State University of Railway Transport, 2012

8. V.A. Liutyi, Dissertation, Ukrainian State University of Railway Transport, 2007

9. O.A. Koniev, Dissertation, Ukrainian State University of Railway Transport, 2014

10. O.A. Zabiiaka, Dissertation, Ukrainian State University of Railway Transport, 2015

11. L.V. Trykoz, Dissertation, Ukrainian State University of Railway Transport, 2015

12. I.V. Strizhevskij, A.D. Belogolovskij, V.I. Dmitriev et al. Zashhita podzemnyh metallicheskih sooruzhenij ot korrozii (Strojizdat, Moskva, 1990)

13. V.V. Kasianov, Dissertation, Ukrainian State University of Railway Transport, 2018

14. V.V. Palyi, Dissertation, Ukrainian State University of Railway Transport, 2014

15. S.H. Nesterenko, Dissertation, Ukrainian State University of Railway Transport, 2016
16. R.A. Rohde, R.A. Muller, Cycles in fossil diversity. Nature 434, 209-210 (2005). doi: 10.1038/nature03339

17. A.D. Ursul, T.A. Ursul, Grjadushhee chelovechestva: gibel' ili bessmertie? Sociodinamika 3, 138-199 (2013). doi:10.7256/2306-0158.2013.3.478

18. I. Klimenko, Global warming is one aspect of climate change (Allatra Science, 2016), https://allatrascience.org/en/publication/globalnoe-poteplenie. Accessed 27 Dec 2019

19. F. Lambert, B. Delmonte, J.R. Petit, M. Bigler, P.R. Kaufmann, M.A. Hutterli, T.F. Stocker, U. Ruth, J.P. Steffensen, V. Maggi. Nature 452, 616-619 (2008)

20. E. Merns, The Vostok Ice Core and the 14,000 Year $\mathrm{CO}_{2}$ Time Lag (Energy Matters, 2014), http://euanmearns.com/the-vostok-ice-coretemperature-co2-and-ch4/. Accessed 26 Dec 2019

21. A.A. Khan, Why would sea-level rise for global warming and polar ice-melt? Geoscience Frontiers 10(2), 481-494 (2019) 